\title{
Feasibility of Upper Gastrointestinal Examination in Home Care Setting with a Magnetically Assisted Capsule Endoscopy System: A Retrospective Study
}

\author{
Yang-Chao Lin ${ }^{1,2,3}{ }^{(1)}$, Ching-Lin Chen ${ }^{2,3}$, Yi-Wei Kao $\left.{ }^{2}{ }^{(}\right)$, Chi-Yang Chang ${ }^{1}$, Ming-Chih Chen ${ }^{2}$ \\ and Chih-Kuang Liu $2,4, *$ \\ 1 Department of Gastroenterology and Hepatology, Fu Jen Catholic University Hospital, \\ New Taipei 242, Taiwan; yangchao.lin@gmail.com (Y.-C.L.); chiyang1112@gmail.com (C.-Y.C.) \\ 2 Graduate Institute of Business Administration, Fu Jen Catholic University, New Taipei 242, Taiwan; \\ a1554@tpech.gov.tw (C.-L.C.); kyw498762030@gmail.com (Y.-W.K.); 081438@mail.fju.edu.tw (M.-C.C.) \\ 3 Taipei City Hospital, Zhong-Xing Branch, Taipei 10341, Taiwan \\ 4 Department of Urology, Fu Jen Catholic University Hospital, New Taipei 242, Taiwan \\ * Correspondence: Charles.jhs@gmail.com
}

Citation: Lin, Y.-C.; Chen, C.-L.; Kao Y.-W.; Chang, C.-Y.; Chen, M.-C.; Liu, C.-K. Feasibility of Upper Gastrointestinal Examination in Home Care Setting with a Magnetically Assisted Capsule Endoscopy System: A Retrospective Study. Healthcare 2021, 9, 577. https://doi.org/10.3390/ healthcare 9050577

Academic Editors: Munjae Lee and Kyu-sung Lee

Received: 17 April 2021

Accepted: 10 May 2021

Published: 13 May 2021

Publisher's Note: MDPI stays neutral with regard to jurisdictional claims in published maps and institutional affiliations.

Copyright: (c) 2021 by the authors. Licensee MDPI, Basel, Switzerland. This article is an open access article distributed under the terms and conditions of the Creative Commons Attribution (CC BY) license (https:// creativecommons.org/licenses/by/ $4.0 /)$.

\begin{abstract}
The magnetic assisted capsule endoscope (MACE) with a hand-held magnetic field navigator (MFN) for upper gastrointestinal examination achieved satisfactory results in a healthy volunteer study. We evaluated the feasibility of upper gastrointestinal examination in the home care setting with the MACE system. Home care patients with upper gastrointestinal symptoms that received an MACE exam were enrolled in the study. MACE procedure time; completeness of observation of important anatomical landmarks; endoscopic diagnosis; patient tolerance during the procedure; and patient data, including age, sex, comorbidities, symptoms, body weight, and height, were retrieved from hospital information system for data analysis. A total of 16 participants were enrolled with a mean age $74.3 \pm 15.4$ years ( 47 to 99 years). One patient failed to swallow the capsule and was excluded. The average procedure time was $23.7 \pm 10.0 \mathrm{~min}$ (14.1 to $42.5 \mathrm{~min}$ ) to complete each endoscopic exam for the remaining 15 patients. The overall maneuverability in the esophagus, stomach, and duodenum was $93.75 \%, 87.5 \%$, and $75 \%$, respectively. Overall completeness in the aforementioned regions was $93.75 \%, 81.25 \%$, and $75 \%$, respectively. No severe adverse events were noted. The results clearly demonstrate the promise of using this MACE system to perform endoscopic examination outside the hospital for patients confined to the community and home.
\end{abstract}

Keywords: magnetic assisted; capsule endoscopy; upper gastrointestinal; home care; peptic ulcer; acid reflux

\section{Introduction}

Two decades have passed since the first commercial capsule endoscopy (CE) was launched in 2000 [1,2]. CE provides an alternative method for inspecting gastrointestinal tracts without discomfort or need for sedation. However, due to lack of operator-controlled navigation, wireless $\mathrm{CE}$ is ineffective for observing saccular organs, such as the stomach or duodenum.

In 2019, Insight Medical Solutions (IMS) introduced the IMS MACE system, a novel magnetic-assisted capsule endoscope (MACE) system with a hand-held magnetic field navigator (MFN). This technology was cleared by the Taiwan Food and Drug Administration for use in Taiwan. Unlike wireless capsule endoscopy in the past [3,4], InsightEyes has two distinguishing features: each capsule endoscope is wired by a thin $(1 \mathrm{~mm})$ and soft cable, which is used for imaging data and power transmission. In addition, when applied with an external magnetic field, the cable plays an important role in maintaining different postures of the capsule and enables complete upper GI examination. Moreover, the relatively compact size of the system makes it highly portable and thus possible for 
physicians to perform upper GI examination in various care settings and even outside the hospital if necessary.

Unlike most other in-building magnetic-controlled capsule endoscopy systems developed in recent decades [5-8], the IMS MACE system is highly portable and thus provides a solution for physicians to perform upper GI endoscopy for patients outside hospital or clinic settings. It is known that peptic ulcer disease and esophageal reflux are common in the senior population [9]. Seniors are prone to co-morbidities such as cardiovascular disease, cerebral vascular disease, degenerative arthritis, and osteoporosis and, as a result, have higher likelihood of taking anti-platelet agents, non-steroidal anti-inflammatory drugs, and bisphosphonates. This may result in acid-related disorders with symptoms such as acid reflux, dyspepsia, epigastric pain or anorexia, and the underlying pathology is mostly neglected unless alarm symptoms develop. Unfortunately, elderly patients with peptic ulcer disorders might have slight or atypical presentation, thus resulting in delayed diagnosis [10]. The current standard of care prevents physicians from performing gastrointestinal endoscopy outside the hospital due to the issue of portability of the endoscopy system. Therefore, senior or disabled patients who have difficulty visiting hospitals or clinics when they encounter gastrointestinal or acid-related symptoms are often underdiagnosed.

In 2015, the Taiwan National Health Institute launched the "Home-based Medical Integration Program". Patients with physical or mental disabilities who are older than 65 with certain physical disabilities and confined to their homes are eligible to apply for the medical integration program. Medical teams of the corresponding hospital provide medical services, such as blood checks, physical examinations, electrocardiograms, abdominal ultrasounds, and medicine prescriptions for patients at their residency. A previous study of this MACE system showed satisfactory results of maneuverability, visual completeness, safety, and tolerance in the examination of upper gastrointestinal tracts of healthy volunteers [11]. Motivated by this program and the identified gap of elderly and disabled patients being underdiagnosed for GI disorders, we launched a study to evaluate the feasibility, tolerability, and safety of a portable MACE system for examining gastrointestinal tracts of senior and home care patients at their residence.

\section{Materials and Methods}

\subsection{Participants}

Among the 256 registered patients in our "Home-based Medical Integration Program", patients who had complaints of dyspepsia, epigastralgia, acid reflux, heartburn, or anorexia since 2015 were reported to our gastroenterologist by nursing staff. The physician first reviewed the medical records and discussed the physical conditions of the patient with community nurses in charge. Then, these patients were arranged for MACE examination if eligible. Patients with known difficulty swallowing, gastric surgery history, any malignancy history, gastrointestinal obstruction, pacemaker implants, or metal implants were excluded from the study. A total of 16 home care patients were enrolled to receive MACE examinations between March 2020 and May 2020.

\subsection{IMS MACE System (Insight Medical Solutions Crop, Hsinchu City, Taiwan)}

The MACE system was packed in an aluminum roller suitcase, which contained disposable InsightEyes ${ }^{\circledR}$ EGD, a hand-held magnetic field navigator (MFN), an Aries E500i image processing unit, and a 21-inch LCD monitor (Figure 1). 


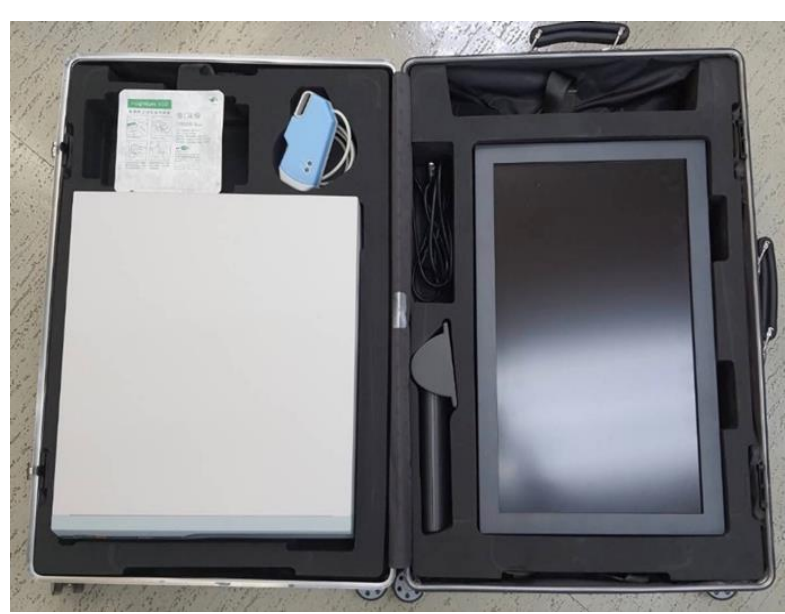

(a)

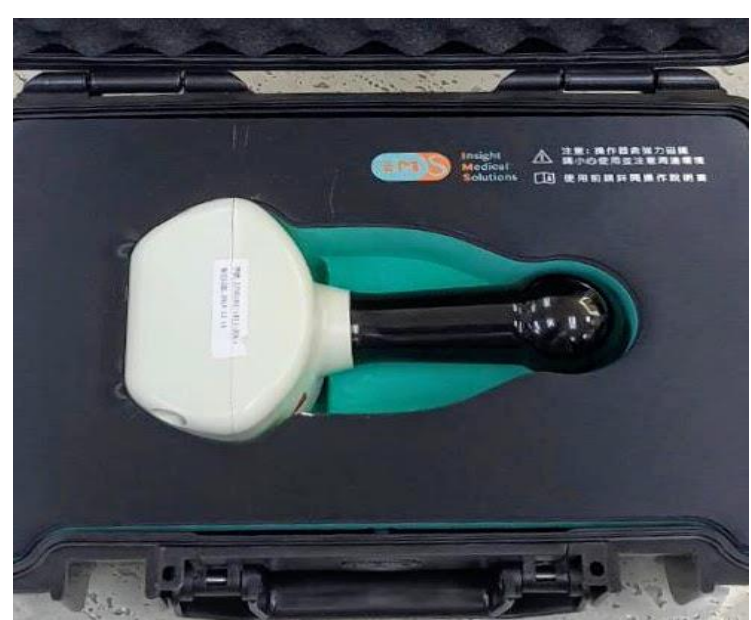

(b)

Figure 1. (a) Image processor, LCD monitor and InsightEyes EGD, packed in a roller suitcase. (b) Hand-held magnetic field navigator.

\subsection{Patient Preparation}

All patients were required to fast for at least 6 hours prior to the exam. A total of $400 \mathrm{mg}$ of $\mathrm{N}$-acetylcysteine tablets for the mucolytic effect dissolved in $500 \mathrm{~mL}$ clear water was administered one hour before examination [12-14]. Additional clear water intake during MACE examination was encouraged if some mucus or bubbles interfered with the observed mucosa.

Upon arriving at the patient's residency, our staff assembled the MACE system, while nursing staff explained the procedure and provided instructions regarding how to swallow the capsule.

\subsection{MACE Examination}

Written consent was obtained before examination, and MACE examinations were carried out in the patients' homes. The medical team included an endoscopist experienced with MACE examinations, a community care nurse who was in-charge of the patient, and an endoscopy technician who aided the patient during the procedure if necessary. Patients were instructed to pinch the string of the CE and put the capsule at the base of the tongue. Patients would then swallow a mouthful of water with the capsule to force the capsule down the esophagus. If the patient has difficulty swallowing the capsule, our nurse helped the patient to place the capsule at the base of the tongue and slightly push the capsule deeper down the throat. During examination, the patient could speak to the doctor if necessary, and the physician could ask the patient to change posture or drink more water. The endoscopist controlled the orientation and movements of the capsule using a hand-held MFN to observe all necessary parts of the upper gastrointestinal tracts. When the examination ended, the patient or our nurse was instructed to slowly pull out the capsule. The esophagus was observed for a second time during withdrawal of the capsule.

The environmental requirement for the MACE procedure is as follows: a chair or bed was used to complete the MACE procedure; patients were instructed to sit on a chair or bed to swallow the CE, and then lie down on a bed or couch after the CE entered the stomach; patients had to change to the left or right decubitus position as necessary when the doctor manipulated the CE.

No intramuscular injection of hyoscine-N-butylbromide or spray of xylocaine on the throat was needed. No vacuum machine or $\mathrm{CO}_{2}$ pump, requirements for traditional esophagogastroduodenoscopy (EGD), was required for the MACE exam. 


\section{Data Collection}

MACE procedure time, completeness of observation of important anatomical landmarks, endoscopic diagnosis, and patient tolerance during endoscopy were our primary data of interest for generating descriptive statistics. The MACE exam report and patients data, including age, sex, comorbidities, symptoms, body weight, and height, were retrieved from the hospital information system with permission from the Taipei City Hospital Research Ethics Committee (TCHIRB-10906010-E).

\section{Statistical Analysis}

Descriptive analysis was applied to address the demographic features of our patients, quality of the MACE examination, diagnostic outcomes, safety, and the tolerability of patients. Maneuverability is defined as the ability of the capsule to be positioned at the specific landmark during examination (\%maneuverability = number of successful positioning/total study number $\times 100 \%$ ). Completeness was defined as the rate of detailed observation of targeted landmarks (\%completeness $=$ number successful observation $/$ total study number $\times 100 \%$ ). A satisfactory result is defined as more than $90 \%$ patients completing the MACE examination with completeness of greater than $90 \%$. In addition, no major complications or equipment malfunction during examination were observed during the examinations.

\section{Results}

Sixteen home care patients (eight female and eight male) were enrolled in this novel MACE study. The mean age was $74.3 \pm 15.4$ years (47 to 99 years). One female patient (case 16, age 83) failed to swallow the capsule by herself and with our assistance, so she was excluded from this study. It took an average of $23.7 \pm 10.0 \mathrm{~min}$ (14.1 to $42.5 \mathrm{~min}$ ) to complete each endoscopic study for the remaining 15 patients. An average of 2.2 attempts (1 to 5 attempts) per patient were taken to successfully swallow the capsule endoscope with or without assistance. Demographics are shown in Table 1.

Table 1. Demographic characteristics of the patients. HTN: hypertension, DM: diabetes mellitus, CAD: coronary artery disease, OA: osteoarthritis, CVA: cerebrovascular accident, HIVD: herniated intervertebral disc, GEGRD: gastroesophageal reflux disease, HCV: hepatitis C virus, GU: gastric ulcer, CP: cerebral palsy, Pul TB: pulmonary tuberculosis, ICH: intracranial hemorrhage, BMI: body mass index.

\begin{tabular}{|c|c|c|c|c|c|c|c|c|c|c|}
\hline Case & Age & Sex & Comorbidites & $\begin{array}{l}\text { Reporting } \\
\text { Symptoms }\end{array}$ & $\begin{array}{l}\text { Procedure } \\
\text { Time } \\
\text { (min) }\end{array}$ & $\begin{array}{l}\text { Time to } \\
\text { Duodenum } \\
\text { (min) }\end{array}$ & $\begin{array}{l}\text { Attempts for } \\
\text { Swallowing }\end{array}$ & $\begin{array}{l}\text { Height } \\
\text { (cm) }\end{array}$ & $\begin{array}{l}\text { Weight } \\
\text { (kg) }\end{array}$ & BMI \\
\hline 1 & 63 & $\mathrm{M}$ & HTN, DM & Heart burn & 30 & NA & 2 & 169 & 60 & 21.0 \\
\hline 2 & 70 & M & $\begin{array}{l}\text { HTN, DM, } \\
\text { CAD, OA }\end{array}$ & Hiccups & 34 & NA & 2 & 155 & 80 & 33.3 \\
\hline 3 & 77 & $\mathrm{~F}$ & $\begin{array}{l}\text { HTN, DM, } \\
\text { CAD, CVA, } \\
\text { HIVD }\end{array}$ & $\begin{array}{l}\text { Dyspepsia, } \\
\text { acid reflux }\end{array}$ & 18 & 12 & 1 & 142 & 72 & 35.7 \\
\hline 4 & 70 & M & $\begin{array}{l}\text { HTN, DM, } \\
\text { CVA }\end{array}$ & $\begin{array}{l}\text { Dyspepsia, } \\
\text { acid reflux }\end{array}$ & 42 & NA & 2 & 160 & 56 & 21.9 \\
\hline 5 & 56 & M & $\begin{array}{c}\text { HTN, HI, } \\
\text { CVA, L't } \\
\text { Hemiplegia }\end{array}$ & $\begin{array}{l}\text { Dyspepsia, } \\
\text { acid reflux }\end{array}$ & 11 & 3 & 4 & 165 & 53 & 19.5 \\
\hline 6 & 82 & $\mathrm{~F}$ & $\begin{array}{l}\text { HTN, CAD, } \\
\text { Asthma }\end{array}$ & $\begin{array}{l}\text { Dyspepsia, } \\
\text { acid reflux }\end{array}$ & 24 & 9 & 2 & 166 & 61 & 22.1 \\
\hline 7 & 91 & M & $\begin{array}{c}\text { HTN, GERD, } \\
\text { DM, HCV }\end{array}$ & $\begin{array}{l}\text { Flatulence, } \\
\text { dyspepsia }\end{array}$ & 19 & 9 & 1 & 150 & 67 & 29.8 \\
\hline 8 & 90 & M & $\begin{array}{l}\text { HTN, DM, } \\
\text { GU, Gout }\end{array}$ & $\begin{array}{l}\text { Dyspepsia, } \\
\text { acid reflux }\end{array}$ & 14 & 3 & 3 & 158 & 46 & 18.4 \\
\hline
\end{tabular}


Table 1. Cont.

\begin{tabular}{|c|c|c|c|c|c|c|c|c|c|c|}
\hline Case & Age & Sex & Comorbidites & $\begin{array}{l}\text { Reporting } \\
\text { Symptoms }\end{array}$ & $\begin{array}{l}\text { Procedure } \\
\text { Time } \\
\text { (min) }\end{array}$ & $\begin{array}{l}\text { Time to } \\
\text { Duodenum } \\
\text { (min) }\end{array}$ & $\begin{array}{l}\text { Attempts for } \\
\text { Swallowing }\end{array}$ & $\begin{array}{l}\text { Height } \\
(\mathrm{cm})\end{array}$ & $\begin{array}{l}\text { Weight } \\
\text { (kg) }\end{array}$ & BMI \\
\hline 9 & 47 & $\mathrm{~F}$ & $\begin{array}{l}\text { CP, Pressure } \\
\text { sore. }\end{array}$ & $\begin{array}{l}\text { Flatulence, } \\
\text { dyspepsia }\end{array}$ & 23 & 13 & 1 & 145 & 68 & 32.3 \\
\hline 10 & 69 & $\mathrm{~F}$ & $\begin{array}{l}\text { HTN, DM, } \\
\text { CAD, OA }\end{array}$ & Dyspepsia & 19 & 5 & 5 & 166 & 65 & 23.6 \\
\hline 11 & 90 & $\mathrm{~F}$ & $\begin{array}{l}\text { Glaucoma, } \\
\text { HTN, DM, } \\
\text { CAD }\end{array}$ & Dyspepsia & 41 & 31 & 4 & 150 & 50 & 22.2 \\
\hline 12 & 87 & M & $\begin{array}{c}\text { HTN, CAD, } \\
\text { GERD, Pul TB. }\end{array}$ & Heart burn & 15 & 11 & 2 & 159 & 45 & 17.8 \\
\hline 13 & 53 & M & $\begin{array}{c}\text { Traffic } \\
\text { Accident, } \\
\text { Quadriplegia }\end{array}$ & Heart burn & 18 & 3 & 1 & 165 & 70 & 25.7 \\
\hline 14 & 62 & $\mathrm{~F}$ & $\begin{array}{c}\text { ICH, R't } \\
\text { hemiplegia }\end{array}$ & Heart burn & 33 & 18 & 1 & 150 & 60 & 26.7 \\
\hline 15 & 99 & $\mathrm{~F}$ & $\begin{array}{l}\text { HTN, DM, } \\
\text { CAD, OA }\end{array}$ & Epigastralgia & 14 & 5 & 2 & 162 & 65 & 24.8 \\
\hline 16 & 83 & $\mathrm{~F}$ & $\begin{array}{c}\text { HTN, CAD, } \\
\text { GU }\end{array}$ & Epigastralgia & NA & NA & 5 & 157 & 60 & 24.3 \\
\hline
\end{tabular}

\subsection{Maneuverability and Completeness of Examination}

One of the sixteen patients failed to swallow the capsule. On the intention-to-treat basis, the maneuverability and completeness in the esophagus were both $93.75 \%$ (see Table 2). There was no difficulty in positioning and observing the gastric body, antrum, pylorus, and angularis using the string-pulled capsule $(93.75 \%$ maneuverability and $93.75 \%$ completeness). However, we failed to observe cardia and fundus in 3 of the 16 patients (18.75\%). One case was due to failed positioning of capsule, and the other case was due to mucus interference.

Table 2. Completeness and maneuverability of MACE for important landmarks of upper gastrointestinal tracts. Completeness was calculated as the number of landmarks observed divided by the number of landmarks that should be observed for a specific organ. Maneuverability was calculated as the number of landmarks reached by the capsule divided by the number of landmarks that should be reached in a particular organ.

\begin{tabular}{|c|c|c|c|c|}
\hline Organ & Landmarks & Completeness & Maneuverability & $\begin{array}{c}\text { Overall } \\
\text { Completeness } \% / \text { Maneuverability } \%\end{array}$ \\
\hline \multirow[t]{5}{*}{ Esophagus } & & & & $93.75 \% / 93.75 \%$ \\
\hline & Upper third & $15(93.75 \%)$ & $15(93.75 \%)$ & \\
\hline & Middle third & $15(93.75 \%)$ & $15(93.75 \%)$ & \\
\hline & Lower third & $15(93.75 \%)$ & $15(93.75 \%)$ & \\
\hline & $\begin{array}{l}\text { Esophago-gastric } \\
\text { junction }\end{array}$ & $15(93.75 \%)$ & $15(93.75 \%)$ & \\
\hline \multirow[t]{7}{*}{ Stomach } & & & & $81.25 \% / 87.5 \%$ \\
\hline & Cardia & $13(81.25 \%)$ & $14(87.5 \%)$ & \\
\hline & Fundus & $13(81.25 \%)$ & $14(87.5 \%)$ & \\
\hline & Body & $15(93.75 \%)$ & $15(93.75 \%)$ & \\
\hline & Antrum & $15(93.75 \%)$ & $15(93.75 \%)$ & \\
\hline & Angle & $15(93.75 \%)$ & $15(93.75 \%)$ & \\
\hline & Pylorus & $15(93.75 \%)$ & $15(93.75 \%)$ & \\
\hline \multirow[t]{3}{*}{ Duodenum } & & & & $75 \% / 75 \%$ \\
\hline & Bulb & $12(75 \%)$ & $12(75 \%)$ & \\
\hline & 2nd portion & $12(75 \%)$ & $12(75 \%)$ & \\
\hline
\end{tabular}


The capsule endoscope failed to pass through the pylorus in four patients (25\%). One patient had marked pyloric stenosis, and the capsule had difficulty traversing to the duodenum in two other patients. As a result, the overall maneuverability and completeness of observing the duodenum were both $75 \%$ and $75 \%$. All capsules reached the second portion in patients whose duodenal bulbs were observed.

\subsection{Tolerability and Safety}

All patients consumed at least $500 \mathrm{~mL}$ of $400 \mathrm{mg} \mathrm{N}$-acetylcysteine dissolved in clear water in preparation for MACE examination. Additional clear water of about $500 \mathrm{~mL}$ was given to each patient to facilitate maneuverability or clearance of bubbles and mucus as necessary. Of the fifteen patients that finished the MACE, none vomited during or after the procedure. Five patients complained of mild nausea and foreign body sensation in the throat. None complained of epigastric pain during examination when the physician manipulated the MFN over their abdomen. No severe adverse events were noted during examination, and all capsules were retrieved with no noticeable problems.

\subsection{Diagnostic Results}

Of the 15 patients who underwent MACE examination, 66.7\% had reflux esophagitis, $46.7 \%$ had gastric erosions, $20 \%$ had gastric ulcers, and $13.3 \%$ had duodenal ulcers, while lesions like hiatus hernia and pyloric stenosis comprised of less than $10 \%$ of the patients.

\section{Discussion}

This novel medical service providing upper gastrointestinal endoscopy for homecare patients using the MACE system revealed a satisfactory preliminary result. Patients tolerated the procedure well, and no noticeable procedure-related complications during or after the endoscopic examinations were observed.

The portability of the MACE system enabled physicians to perform upper GI endoscopic examinations at the patients' residencies, which is unprecedented. In our study, most of the patients ( 15 of 16 patients, $93.75 \%$ ) successfully finished the MACE examination, and diagnostic results helped the physicians to pinpoint the exact diagnosis and provide recommended therapy. However, we did notice some limitations and technical issues to be solved in the near future.

Completeness of the MACE examination is one of the major considerations on whether MACE is a suitable device for examining upper GI tracts. The image quality of this MACE system was good enough for the physician to observe desired landmarks (Figure 2). The ability of detailed observation of mucosa through the endoscope was essential for the endoscopist to make a precise diagnosis. A previous study of MACE on healthy volunteers in 2017 showed 100\% completeness in the esophagus, 85.2\% in the stomach, and $86.2 \%$ in the duodenum [11]. Similar results were reported in a systemic review [15], and the overall completeness of observing essential landmarks of the esophagus, stomach, and duodenum were $93.75 \%, 81.25 \%$, and $75 \%$, respectively, in our study. However, cardia and fundus were not clearly observed in $18.75 \%$ of patients. Two factors might contribute to the insufficient completeness of observation: one factor is related to mucosa obscured by redundant bubbles or mucus, which may result from inadequate gastric preparation. The other is related to difficulty in maneuvering the capsule in certain patients. After reviewing the video recordings of each examination, maneuverability of the capsule to observe the cardia and fundus was achieved during examination, but it was difficult for the physicians to remove the bubbles from the surfaces of mucosa despite changes in positions or additional water intake. The postural limitation of senior patients further made it difficult to manipulate the MFN. Thus, pre-MACE gastric preparation is likely a key factor to improve the quality of capsule endoscopy. In addition, the capsule failed to pass through the pyloric ring in 4 of the 16 patients $(25 \%)$, with one of the patients being found to have pyloric stenosis. It was crucial for the physician to manipulate the capsule as close as possible to the pyloric ring, waiting for gastric peristalsis while keeping magnetic 
traction of the capsule toward the duodenal bulb. However, MACE lacks a shaft push force like the traditional endoscope, and the real-world completeness of duodenal observation $(75 \%)$ was inferior to that of a previous health pioneer study $(86.1 \%)$ [11].

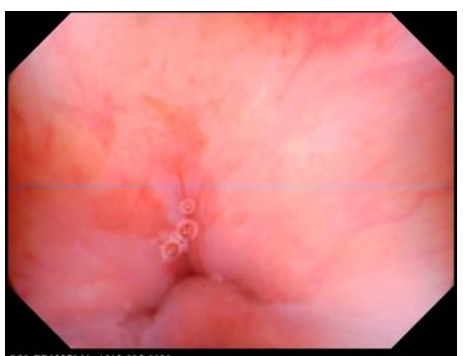

(a)

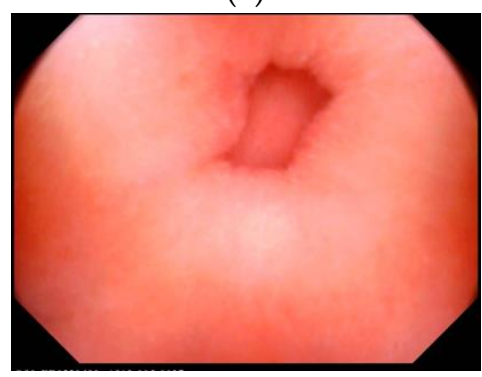

(d)

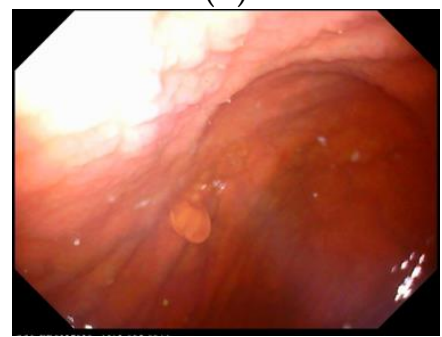

$(\mathrm{g})$

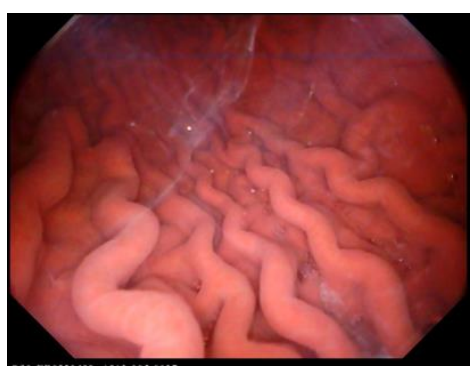

(b)

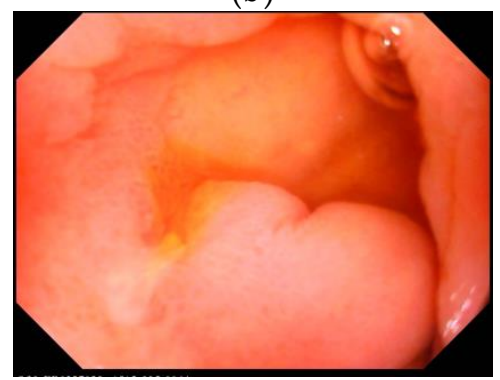

(e)

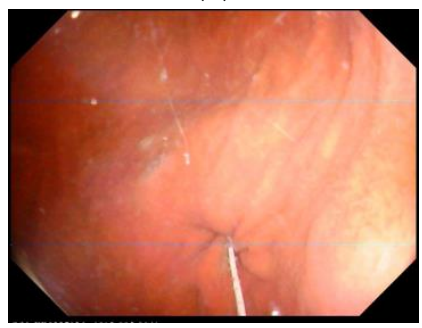

(h)

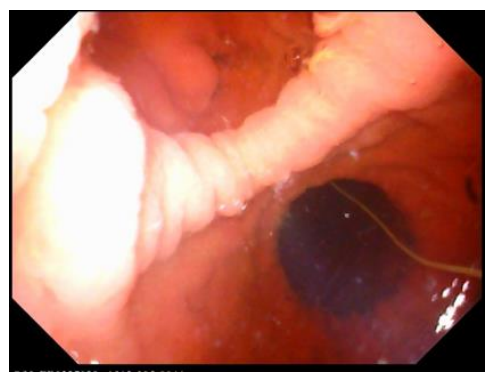

(c)

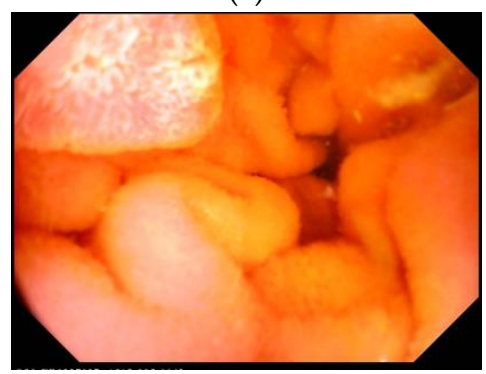

(f)

Figure 2. Landmark images of the upper gastrointestinal tracts by magnetic-assisted capsule endoscopy. (a) Esophagogastric junction, (b) gastric body, (c) antrum and angularis, (d) pylorus, (e) duodenal bulb, (f) duodenal second portion, (g) fundus, (h) cardia.

Adverse events of capsule endoscopy, such as rate of retention, aspiration, and procedure-related adverse events, were known to be less than $1 \%$ in a systemic review [15]. In our patients, none of the participants reported vomiting or choking during or after the MACE examination, with only 5 patients complaining of nausea and foreign body sensation in the throat. None of the reported discomforts interrupted the procedure, and every capsule was retrieved successfully after examination. The results of safety and tolerability were encouraging, because the elderly and disabled patients were especially vulnerable to choking and aspiration.

The mean procedure time was $23.7 \mathrm{~min} \pm 10.0 \mathrm{~min}$. The longest time to complete the examination was $42 \mathrm{~min}$ for a 70 -year-old male, who had pyloric stenosis, and the capsule eventually failed to pass to the duodenum after several attempts. The time for the capsule to pass to the duodenum seemed to be an important determining factor on procedure time. Thus, we further divided the patients into two groups for timing analysis: the duodenal group $(\mathrm{n}=12)$ and the non-duodenal group ( $\mathrm{n}=3$; failed to pass the pylorus). The results were $20.75 \mathrm{~min}$ for the duodenal group vs. $35.33 \mathrm{~min}$ for the non-duodenal group, with a statistically significant difference ( $95 \% \mathrm{CI}=2.91-26.23, p=0.02497)$. The sample size was small, and a future study should be conducted to further clarify if the time for the capsule to traverse the pylorus is a critical factor in determining the procedure time. 
This study had several limitations: first, this is a retrospective study, which lacked a control group for comparison of all measurable parameters; second, a small study population may result in exaggerated selection bias. Thus, a prospective study with a larger sample size should be considered.

\section{Conclusions}

This is the first real-world study of the MACE system to be utilized in home care patients. The results showed that the MACE system for in-home use was satisfactory in relation to patient safety and tolerance. Observation of the esophagus was satisfactory, but maneuverability and completeness in the stomach and duodenum were less than $90 \%$ in this study. However, these results clearly demonstrate the possibility of using this MACE system to perform endoscopic examination outside the hospital setting for patients confined to the community and home.

Author Contributions: Y.-C.L. and C.-L.C. conceived the study framework and received comments and study method suggestions from M.-C.C. and C.-K.L., Y.-W.K. and C.-Y.C. contributed to data collection and analysis. The manuscript was completed by Y.-C.L. and reviewed by all the other authors. All authors have read and agreed to the published version of the manuscript.

Funding: This research received no external funding.

Institutional Review Board Statement: The study was conducted according to the guidelines of the Declaration of Helsinki and approved by the Institutional Research Ethics Committee of Taipei City Hospital (protocol code TCHIRB-10906010-E, 1 July 2020).

Informed Consent Statement: Informed consent was obtained from all subjects involved in the study.

Data Availability Statement: The data presented in this study are available on request from the corresponding author. The data are not publicly available due to patient privacy.

Acknowledgments: The authors thank technical supports of MACE system by IMS corporation, and appreciate the collaborate work by members of community care division, Zhong-Xing Branch, Taipei City Hospital.

Conflicts of Interest: The authors declare that there are no conflict of interest regarding the publication of this paper.

\section{References}

1. Iddan, G.; Meron, G.; Glukhovsky, A.; Swain, P. Wireless capsule endoscopy. Nature 2000, 405, 417. [CrossRef] [PubMed]

2. Gong, F.; Swain, P.; Mills, T. Wireless endoscopy. Gastrointest. Endosc. 2000, 51, 725-729. [CrossRef]

3. Singeap, A.M.; Stanciu, C.; Trifan, A. Capsule endoscopy: The road ahead. World J. Gastroenterol. 2016, 22, 369-378, [CrossRef] [PubMed]

4. Nakamura, T.; Terano, A. Capsule endoscopy: Past, present, and future. J. Gastroenterol. 2008, 43, 93-99. [CrossRef] [PubMed]

5. Cheng, C.S.; Sun, T.J.; Zhang, H.D. Human gastric magnet-controlled capsule endoscopy conducted in a standing position: The phase 1 study. BMC Gastroenterol. 2019, 19, 184. [CrossRef] [PubMed]

6. Rey, J.F.; Ogata, H.; Hosoe, N.; Ohtsuka, K.; Ogata, N.; Ikeda, K.; Aihara, H.; Pangtay, I.; Hibi, T.; Kudo, S.; et al. Feasibility of stomach exploration with a guided capsule endoscope. Endoscopy 2010, 42, 541-545. [CrossRef] [PubMed]

7. Oh, D.J.; Kim, K.S.; Lim, Y.J. A New Active Locomotion Capsule Endoscopy under Magnetic Control and Automated Reading Program. Clin. Endosc. 2020, 53, 395-401. [CrossRef] [PubMed]

8. Liao, Z.; Duan, X.D.; Xin, L.; Bo, L.M.; Wang, X.H.; Xiao, G.H.; Hu, L.H.; Zhuang, S.L.; Li, Z.S. Feasibility and safety of magnetic-controlled capsule endoscopy system in examination of human stomach: A pilot study in healthy volunteers. J. Interv. Gastroenterol. 2012, 2, 155-160. [CrossRef] [PubMed]

9. Tang, R.S.; Wu, J.C. Managing peptic ulcer and gastroesophageal reflux disease in elderly Chinese patients-Focus on esomeprazole. Clin. Interv. Aging 2013, 8, 1433-1443. [PubMed]

10. Franceschi, M.; Di Mario, F.; Leandro, G.; Maggi, S.; Pilotto, A. Acid-related disorders in the elderly. Best Pract. Res. Clin. Gastroenterol. 2009, 23, 839-848. [CrossRef] [PubMed]

11. Lien, G.S.; Wu, M.S.; Chen, C.N.; Liu, C.W.; Suk, F.M. Feasibility and safety of a novel magnetic-assisted capsule endoscope system in a preliminary examination for upper gastrointestinal tract. Surg. Endosc. 2018, 32, 1937-1944. [CrossRef] [PubMed]

12. Chang, C.C.; Chen, S.H.; Lin, C.P.; Hsieh, C.R.; Lou, H.Y.; Suk, F.M.; Pan, S.; Wu, M.S.; Chen, J.N.; Chen, Y.F. Premedication with pronase or $\mathrm{N}$-acetylcysteine improves visibility during gastroendoscopy: An endoscopist-blinded, prospective, randomized study. World J. Gastroenterol. 2007, 13, 444-447. [CrossRef] [PubMed] 
13. Chang, W.K.; Yeh, M.K.; Hsu, H.C.; Chen, H.W.; Hu, M.K. Efficacy of simethicone and N-acetylcysteine as premedication in improving visibility during upper endoscopy. J. Gastroenterol. Hepatol. 2014, 29, 769-774. [CrossRef] [PubMed]

14. Elvas, L.; Areia, M.; Brito, D.; Alves, S.; Saraiva, S.; Cadime, A.T. Premedication with simethicone and N-acetylcysteine in improving visibility during upper endoscopy: A double-blind randomized trial. Endoscopy 2017, 49, 139-145. [CrossRef] [PubMed]

15. Wang, Y.C.; Pan, J.; Liu, Y.W.; Sun, F.Y.; Qian, Y.Y.; Jiang, X.; Zou, W.B.; Xia, J.; Jiang, B.; Ru, N.; et al. Adverse events of video capsule endoscopy over the past two decades: A systematic review and proportion meta-analysis. BMC Gastroenterol. 2020, 20, 364. [CrossRef] [PubMed] 